\title{
A Pilot Comparative Study of 26 Biochemical Markers in Seminal Plasma and Serum in Infertile Men
}

\author{
Rui-Xiang Feng, ${ }^{1}$ Jin-Chun Lu, ${ }^{1}$ Hong-Ye Zhang, ${ }^{2}$ and Nian-Qing Lüi ${ }^{3}$ \\ ${ }^{1}$ Department of Laboratory Science, Nanjing Hospital, Jiangsu Corps, The Armed Police Force, PLA, Nanjing 210028, China \\ ${ }^{2}$ Department of Laboratory Science, Nanjing Hospital Affiliated to Nanjing Medical University, Nanjing 210006, China \\ ${ }^{3}$ Jiangsu Family Planning Research Institute, Nanjing 210036, China \\ Correspondence should be addressed to Jin-Chun Lu; lujc@androl.cn and Nian-Qing Lü; nq.lu2009@gmail.com
}

Received 6 April 2015; Accepted 25 June 2015

Academic Editor: Katrien Stouffs

Copyright (C) 2015 Rui-Xiang Feng et al. This is an open access article distributed under the Creative Commons Attribution License, which permits unrestricted use, distribution, and reproduction in any medium, provided the original work is properly cited.

Introduction. The relationships of the biochemical components in seminal plasma and serum, and their origins and physiological effects in male reproductive system have been poorly understood. Methods. Based on the calibration and quality control measures, 26 biochemical markers, in seminal plasma and serum samples from 36 male infertility patients with nonazoospermia were detected and compared. Results. Only PA was undetectable in all seminal plasma samples. There were significant differences of all other 24 biochemical markers in seminal plasma and serum $(P<0.05)$ except for UA $(P=0.214)$. There were rich proteins in seminal plasma, and globulin accounted for about $90 \%$. There were also abundant enzymes in seminal plasma, and the activities of ALT, AST, AKP, GGT, LDH, CK, and $\alpha \mathrm{HBDH}$ in seminal plasma were significantly higher than those in serum while ADA was inversely lower. There were relatively low levels of Glu, TG, TC, and hsCRP in seminal plasma, but Glu was undetectable in 8 of 36 cases. Conclusions. The differences of the levels of biochemical markers in seminal plasma and serum might be associated with the selective secretion of testis, epididymis and male accessory glands, and the specific environment needed for sperm metabolism and function maintenance.

\section{Introduction}

Currently, alpha-glucosidase, acid phosphatase, zinc, and fructose levels in seminal plasma have been determined in clinical andrology laboratories to evaluate the secretion function of male accessory glands [1-3]. Like serum, seminal plasma consists of rich biochemical components. It has been shown recently that seminal plasma proteins could serve as important biomarkers for male infertility [4]. In addition, functional proteomic analysis revealed that proteins are overor underexpressed in the seminal plasma of men with poor semen quality [5]. However, the origins of these components and their correlations with those in serum are unclear. It is also unknown whether these components could be used to evaluate male fertility. Several studies have been done to compare the levels of biochemical markers in seminal plasma and serum, most of these studies focused on animal reproduction, and investigations on biochemical markers were limited. Moreover, the origins and potential physiological effects of biochemical components in seminal plasma have been still poorly understood; thus, we designed this study to detect the levels of 26 kinds of biochemical markers in seminal plasma and serum on the basis of quality control for each marker, and all the data were compared and analyzed.

\section{Materials and Methods}

2.1. Reagents. Kits for the determinations of total protein (TP), albumin (Alb), alanine aminotransferase (ALT), aspartate aminotransferase (AST), alkaline phosphatase (AKP), and calcium (Ca) (Biosino Bio-Technology and Science Inc., Beijing, China), prealbumin (PA), high-sensitive C-reactive protein (hsCRP), gamma-glutamyl transpeptidase (GGT), lactate dehydrogenase $(\mathrm{LDH})$, urea $(\mathrm{Ur})$, creatinine $(\mathrm{Cr})$, uric acid (UA), glucose (Glu), creatine kinase (CK), and adenosine deaminase (ADA) (Ningbo Medical System Biotechnology Co., Ltd., Ningbo, China), triglyceride (TG) and total 
cholesterol (TC) (Shanghai Zhicheng Biotechnology Co., Ltd., Shanghai, China), alpha-hydroxybutyrate dehydrogenase $(\alpha \mathrm{HBDH})$ (Zhejiang Dongou Diagnostics Co., Ltd., Wenzhou, China), magnesium (Mg) and phosphorus (P) (Shanghai Fosun Long March Medical Science Co., Ltd., Shanghai, China), and potassium $\left(\mathrm{K}^{+}\right)$, sodium $\left(\mathrm{Na}^{+}\right)$, and chlorine $\left(\mathrm{Cl}^{-}\right)$(Nanjing Panstar Electronics Instruments Co., Ltd., Nanjing, China) are commercially available from the abovementioned suppliers. Calibration and quality control products were provided by Randox Laboratories Ltd., Northern Ireland, United Kingdom.

2.2. Instruments. Olympus AU400 Automatic Biochemical Analyzer (Olympus Optical Co., Ltd., Tokyo, Japan), PSD16a Electrolyte Analyzer (Nanjing Panstar Electronics Instruments Co., Ltd., Nanjing, China), and TGL-16B High Speed Centrifuge (Shanghai Anting Scientific Instrument Factory, Shanghai, China) were used to determine biochemical markers in this study.

2.3. Samples. All seminal plasma and serum samples were collected in the clinics of the Department of Reproduction and Genetics, Jinling Hospital, School of Medicine, Nanjing University, Nanjing, China. Thirty six (36) infertility patients with nonazoospermia for over 1 year, aged from 26 to 33 years, who self-reported no other disorders, were included in this study. After abstinence for 2 to 7 days, semen samples were collected by masturbation, and for serum samples collection, fasting venous blood was drawn. Semen samples were placed at $37^{\circ} \mathrm{C}$ for liquefaction, followed by routine semen analysis, and the remaining semen samples were centrifuged at $12000 \times \mathrm{g}$ for 5 minutes. The upper layer seminal plasma was collected for the determinations of biochemical markers. Blood samples were centrifuged at $3000 \times \mathrm{g}$ for 5 minutes to isolate serum for the same analyses as for seminal plasma. All semen samples of nonliquefaction and volume less than $1.5 \mathrm{~mL}$ were excluded to avoid potential influence on the accuracy of sampling [6] and ensure all biochemical markers to be detected.

2.4. Biochemical Analysis. First, the calibration and the determination of quality control products for all biochemical markers were performed. After all results of quality control products were within the permitted ranges, the concentrations of $\mathrm{K}^{+}, \mathrm{Na}^{+}$, and $\mathrm{Cl}^{-}$in seminal plasma and serum specimens were detected with a PSD-16a Electrolyte Analyzer and all other biochemical markers determined with Olympus AU400 Automatic Biochemical Analyzer. The samples outside of the linearity of the method and instrumentation were diluted to obtain effective results. All serum samples were directly determined without any dilution, while the measurements of $\mathrm{LDH}, \mathrm{CK}, \alpha \mathrm{HBDH}, \mathrm{K}^{+}, \mathrm{Ca}$, and $\mathrm{Mg}$ in seminal plasma were conducted after $1: 5$ dilution, and $1: 25$ dilution for GGT and P. The seminal plasma samples for the measurements of $\mathrm{LDH}, \mathrm{CK}, \alpha \mathrm{HBDH}, \mathrm{Ca}, \mathrm{Mg}, \mathrm{GGT}$, and $\mathrm{P}$ were diluted with normal saline, and that for $\mathrm{K}^{+}$was diluted with deionized water.

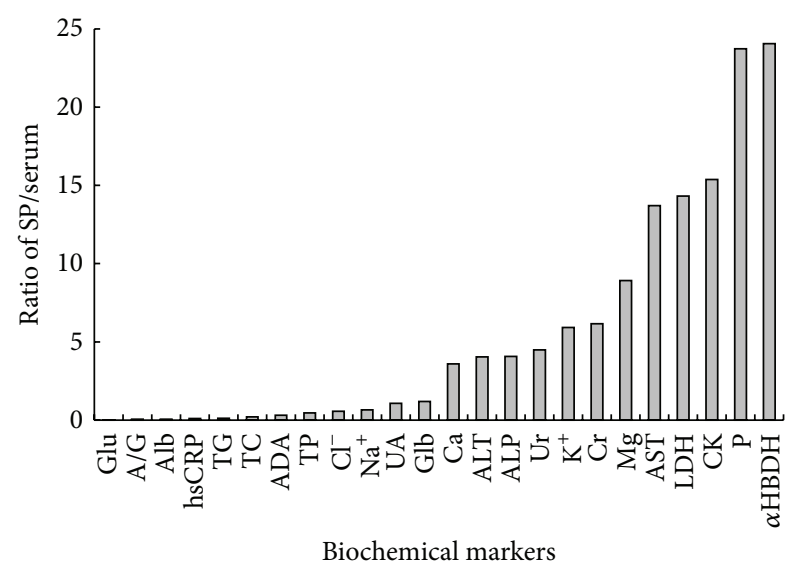

FIgURE 1: Ratios of 24 seminal plasma (SP) and serum biochemical markers except PA (undetectable) and GGT (the ratio of SP/serum up to 543.54).

2.5. Statistical Analysis. All data were saved in the Excel tables and analyzed with the SPSS 11.0 software (SPSS Inc., Chicago, USA). The values of biochemical markers in seminal plasma and serum were presented as mean \pm standard deviation and compared by paired $t$-test, and $P<0.05$ was considered as significant difference. The correlation of biochemical markers in seminal plasma and serum was analyzed with Pearson analysis, and $P<0.05$ was considered as significant correlation.

\section{Results}

The comparison of the results of biochemical markers in seminal plasma and serum was shown in Table 1. Among all 26 kinds of biochemical markers, PA were undetectable, and there was no significant difference of UA in seminal plasma and serum $(P=0.214)$, but all the results of other 24 markers in seminal plasma and serum had significant difference $(P<0.05)$. The levels of Glb, ALT, AST, ALP, GGT, $\mathrm{LDH}, \mathrm{Ur}, \mathrm{Cr}, \mathrm{CK}, \alpha \mathrm{HBDH}, \mathrm{K}^{+}, \mathrm{Ca}, \mathrm{Mg}$, and $\mathrm{P}$ in seminal plasma were significantly higher than those in serum, while the levels of TP, Alb, A/G, ADA, Glu, TG, TC, $\mathrm{Na}^{+}, \mathrm{Cl}^{-}$, and hsCRP in seminal plasma were significantly lower than those in serum (Figure 1). The level of seminal plasma Glu in 8 out of 36 cases was undetectable. The correlation analysis for 24 kinds of biochemical markers except PA (undetectable in seminal plasma) and A/G (with the same value) showed no obvious correlation of biochemical markers except significant positive correlations of UA $(r=0.513, P<0.01)$ and hsCRP $(r=0.861, P<0.01)$, significant negative correlation of Glu $(r=-0.356, P<0.05)$, and some negative correlation of TC $(r=-0.328, P=0.051)$ in seminal plasma and serum.

\section{Discussion}

Over the past seven decades, seminal plasma have been extensively studied. However, the comparison of biochemical markers in seminal plasma and serum has been poorly 
TABLE 1: Comparison of biochemical parameters in seminal plasma and serum $(n=36)$.

\begin{tabular}{|c|c|c|c|c|}
\hline Parameters & Seminal plasma (SP) & Serum & Ratio (SP/serum) & Correlation $(r)$ \\
\hline Total protein $(\mathrm{TP})(\mathrm{g} / \mathrm{L})$ & $33.91 \pm 6.99$ & $74.67 \pm 3.83^{*}$ & $0.46 \pm 0.09$ & 0.063 \\
\hline Albumin (Alb) (g/L) & $2.87 \pm 0.51$ & $48.30 \pm 1.93^{*}$ & $0.060 \pm 0.011$ & 0.112 \\
\hline Globulin $(\mathrm{Glb})(\mathrm{g} / \mathrm{L})$ & $31.05 \pm 6.86$ & $26.37 \pm 3.09^{*}$ & $1.19 \pm 0.27$ & 0.166 \\
\hline Albumin/globulin (A/G) & $0.10 \pm 0.00$ & $1.86 \pm 0.22^{*}$ & $0.055 \pm 0.0065$ & - \\
\hline Prealbumin $(\mathrm{PA})(\mathrm{mg} / \mathrm{L})$ & Undetected & $344.63 \pm 68.17^{*}$ & - & - \\
\hline $\begin{array}{l}\text { Alanine aminotransferase } \\
(\mathrm{ALT})(\mathrm{U} / \mathrm{L})\end{array}$ & $76.75 \pm 24.29$ & $28.39 \pm 24.59^{*}$ & $4.04 \pm 2.57$ & 0.042 \\
\hline $\begin{array}{l}\text { Aspartate aminotransferase } \\
(\mathrm{AST})(\mathrm{U} / \mathrm{L})\end{array}$ & $439.31 \pm 110.57$ & $34.61 \pm 12.31^{*}$ & $13.71 \pm 4.55$ & -0.043 \\
\hline $\begin{array}{l}\text { Alkaline phosphatase } \\
(\mathrm{AKP})(\mathrm{U} / \mathrm{L})\end{array}$ & $311.33 \pm 337.10$ & $79.61 \pm 19.65^{*}$ & $4.07 \pm 4.24$ & 0.107 \\
\hline $\begin{array}{l}\text { Gamma-glutamyl } \\
\text { transpeptidase (GGT) } \\
(\mathrm{U} / \mathrm{L})\end{array}$ & $12133.33 \pm 4278.56$ & $36.31 \pm 34.96^{*}$ & $543.54 \pm 344.21$ & 0.006 \\
\hline $\begin{array}{l}\text { Lactate dehydrogenase } \\
(\mathrm{LDH})(\mathrm{U} / \mathrm{L})\end{array}$ & $2427.08 \pm 724.34$ & $172.11 \pm 26.17^{*}$ & $14.32 \pm 4.54$ & 0.115 \\
\hline $\begin{array}{l}\text { Adenosine deaminase } \\
(\mathrm{ADA})(\mathrm{U} / \mathrm{L})\end{array}$ & $2.92 \pm 1.11$ & $9.58 \pm 2.31^{*}$ & $0.31 \pm 0.12$ & 0.109 \\
\hline Urea $(\mathrm{Ur})(\mathrm{mmol} / \mathrm{L})$ & $24.00 \pm 3.81$ & $5.58 \pm 1.20^{*}$ & $4.49 \pm 1.23$ & 0.185 \\
\hline Creatinine $(\mathrm{Cr})(\mu \mathrm{mol} / \mathrm{L})$ & $505.61 \pm 147.19$ & $82.77 \pm 6.97^{*}$ & $6.15 \pm 1.86$ & -0.011 \\
\hline Uric acid $(\mathrm{UA})(\mu \mathrm{mol} / \mathrm{L})$ & $383.14 \pm 105.44$ & $363.56 \pm 74.61$ & $1.07 \pm 0.25$ & $0.513^{\triangle}$ \\
\hline Glucose (Glu) (mmol/L) & $0.073 \pm 0.095$ & $5.30 \pm 0.60^{*}$ & $0.0147 \pm 0.20$ & $-0.356^{\#}$ \\
\hline $\begin{array}{l}\text { Triglyceride (TG) } \\
(\mathrm{mmol} / \mathrm{L})\end{array}$ & $0.12 \pm 0.11$ & $1.56 \pm 0.98^{*}$ & $0.11 \pm 0.13$ & -0.168 \\
\hline $\begin{array}{l}\text { Total cholesterol (TC) } \\
(\mathrm{mmol} / \mathrm{L})\end{array}$ & $0.90 \pm 0.50$ & $4.92 \pm 1.00^{*}$ & $0.20 \pm 0.13$ & -0.328 \\
\hline Creatine kinase $(\mathrm{CK})(\mathrm{U} / \mathrm{L})$ & $1725.56 \pm 1730.48$ & $128.67 \pm 41.22^{*}$ & $15.37 \pm 19.79$ & -0.111 \\
\hline $\begin{array}{l}\text { Alpha-hydroxybutyrate } \\
\text { dehydrogenase }(\alpha \mathrm{HBDH}) \\
(\mathrm{U} / \mathrm{L})\end{array}$ & $2898.61 \pm 1506.08$ & $122.06 \pm 20.09^{*}$ & $24.06 \pm 12.02$ & 0.157 \\
\hline Potassium $\left(\mathrm{K}^{+}\right)(\mathrm{mmol} / \mathrm{L})$ & $24.06 \pm 5.82$ & $4.10 \pm 0.29^{*}$ & $5.92 \pm 1.58$ & -0.144 \\
\hline Sodium $\left(\mathrm{Na}^{+}\right)(\mathrm{mmol} / \mathrm{L})$ & $93.78 \pm 9.66$ & $142.73 \pm 1.52^{*}$ & $0.66 \pm 0.069$ & -0.112 \\
\hline Chlorine $\left(\mathrm{Cl}^{-}\right)(\mathrm{mmol} / \mathrm{L})$ & $56.54 \pm 11.37$ & $101.86 \pm 1.44^{*}$ & $0.56 \pm 0.11$ & -0.087 \\
\hline Calcium $(\mathrm{Ca})(\mathrm{mmol} / \mathrm{L})$ & $8.47 \pm 2.86$ & $2.37 \pm 0.10^{*}$ & $3.59 \pm 1.24$ & -0.050 \\
\hline $\begin{array}{l}\text { Magnesium }(\mathrm{Mg}) \\
(\mathrm{mmol} / \mathrm{L})\end{array}$ & $6.70 \pm 2.62$ & $0.76 \pm 0.052^{*}$ & $8.92 \pm 3.51$ & -0.105 \\
\hline Phosphorus (P) (mmol/L) & $24.89 \pm 7.16$ & $1.08 \pm 0.20^{*}$ & $23.73 \pm 8.11$ & -0.065 \\
\hline $\begin{array}{l}\text { High-sensitive C-reactive } \\
\text { protein }(\mathrm{hsCRP})(\mathrm{mg} / \mathrm{L})\end{array}$ & $0.066 \pm 0.064$ & $2.05 \pm 4.78^{*}$ & $0.097 \pm 0.091$ & $0.861^{\triangle}$ \\
\hline
\end{tabular}

The data were presented as mean \pm standard deviation. ${ }^{*} P<0.05$ versus the corresponding parameter in seminal plasma. ${ }^{\#} P<0.05$ and ${ }^{\triangle} P<0.01$ for the correlation of the same parameter in seminal plasma and serum.

documented. So far, up to 19 biochemical markers have been reported, and the seminal plasma samples were obtained from 6 patients with spinal cord injury and 6 volunteers [7]. Rosecrans et al. [8] reported 16 biochemical markers, including $\mathrm{Ca}, \mathrm{Mg}, \mathrm{K}^{+}, \mathrm{Na}^{+}, \mathrm{Cl}^{-}, \mathrm{Zn}, \mathrm{P}$, glycerylphosphorylcholine (GPC), carnitine, fructose, UA, acid phosphatase (ACP), AKP, AST, LDH, and ALT in seminal plasma and serum from 24 volunteers, and their results showed that the levels of all biochemical markers except UA between seminal plasma and serum were significantly different $(P<0.05)$. Our results presented in this study were similar to them. Rosecrans et al. [8] also reported that there were significant correlations of $\mathrm{K}^{+}(r=0.51)$, carnitine $(r=0.54)$, and AST $(r=0.70)$ in seminal plasma and serum, but we have not observed such phenomena in present study. Other comparative studies on biochemical markers in seminal plasma and serum were focused mostly on a single marker, such as the level of $\mathrm{Mg}$ in seminal plasma and serum samples obtained from normal fertile men and patients with premature ejaculation [9], and the levels of $\mathrm{Ca}$ and $\mathrm{Mg}$ in seminal plasma and serum from 
113 men [10]. Moreover, the levels of protein, electrolytes, enzymes, and other components in seminal plasma samples in animals such as brown bears [11], rabbits [12], stallion [13], and bactrian camels [14] have been investigated, but the useful information was very limited in these studies.

In present study, we investigated the levels of the other 26 biochemical markers in seminal plasma except alphaglucosidase, acid phosphatase, fructose, and zinc, which had been extensively evaluated for their standardized operation and quality control [1-3]. In order to avoid potential influence of particles in semen, such as sperm, lecithin body on the level, and the determination method of biochemical components in seminal plasma, seminal plasma was isolated from semen samples by centrifugation at $12000 \times \mathrm{g}$ for 5 minutes. The results of preliminary experiments for such seminal plasma samples showed good repeatability $(\mathrm{CV}<5 \%)$. In previous studies [1-3], we have shown that there were still many spermatozoa in some seminal plasma samples obtained at $3000 \times$ g centrifugation for 15 minutes. So, the inconsistency for some previously reported results may be due to the sperm residue in seminal plasma. Second, we obtained the results of all 26 markers from samples with the volume above $1.5 \mathrm{~mL}$ and ensured the accuracy of all results for the calibration and quality control measures made. All these efforts provided a guarantee for drawing meaningful conclusions.

Similar to serum, seminal plasma is composed of various components, and each of them has physiological significance. von Wolff et al. [15] reported that the injection of cryopreserved seminal plasma into the cervix and the posterior fornix of the vagina just after follicle aspiration in IVF or intracytoplasmic sperm injection (ICSI) treatment cycles has the potential to improve pregnancy rate. Moreover, seminal plasma was important for sperm metabolism, the maintenance of sperm function, and the survival and transport of sperm in the female reproductive tract. Our results showed that despite the fact that the UA levels in seminal plasma and serum were comparable, the other markers were significantly different in seminal plasma and serum, suggesting that the origins of the biochemical components in seminal plasma may be the secretion of epithelial cells in the reproductive tract, Sertoli cells, and spermatogenic cells in the male reproductive system for the existence of blood-testis, bloodepididymis barrier and other barriers.

Over 2545 unique proteins in seminal plasma have been identified [16]. In our studies, TP level in seminal plasma was $33.91 \pm 6.99 \mathrm{~g} / \mathrm{L}$, close to the level of $37.9 \pm 5.606 \mathrm{~g} / \mathrm{L}$ reported by Verdejo et al. [17]. Unlike serum, the dominant proteins in seminal plasma were globulins, which accounted for $90 \%$ of TP, while albumin accounted for about $10 \%$. Previous studies [7, 18-21] described the possible role of albumin in seminal plasma. However, there were abundant globulins in seminal plasma, and their roles in male reproduction have been poorly understood. Moreover, in contrast to the previously reported results [22], our findings showed that PA was undetectable in seminal plasma.

A great number of enzymes in seminal plasma have been investigated. Guerin et al. [23] reported that the existence mode of enzymes in seminal plasma was similar to that in sperm, indicating that the enzymes in seminal plasma might play a role in ensuring the normal metabolism of sperm. Our results showed that the activity of ALT and AST was $76.75 \pm$ 24.29 U/L and 439.31 $\pm 110.57 \mathrm{U} / \mathrm{L}$, respectively; both of them were significantly higher than those in serum; in particular AST activity in seminal plasma was 13.71 times higher than that in serum, similar to the result reported by Hirsch et al. [7], that is, ALT: $62.3 \pm 25.7$ IU/L and GOT: $412 \pm 191.1 \mathrm{IU} / \mathrm{L}$. Mortimer and Bramley [24] also reported that the level of AST in seminal plasma was about 15 times higher than that in serum. Moreover, as reported by Dhami and Kodagali [25], the activity of ALT was positively correlated with that of AST $(r=0.514, P=0.001)$. Whether ALT and AST in seminal plasma were derived from testis, epididymis, prostate, or seminal vesicle $[7,13,26]$ was uncertain. In general, high activity of ALT and AST in seminal plasma might have some adverse effects on sperm function [25, 27-30], which may be used as a marker to evaluate sperm quality. However, further studies are needed to analyse the origins of the high levels of ALT and AST in seminal plasma, and we might speculate that some of damaged sperm or epithelial cells in the reproductive tract contribute to such elevated ALT and AST levels in seminal plasma.

GGT and AKP are two important enzymes that reflect hepatobiliary function. Our results showed that the levels of AKP and GGT in seminal plasma were $311.33 \pm 337.10 \mathrm{U} / \mathrm{L}$ and $12133.33 \pm 4278.56 \mathrm{U} / \mathrm{L}$, respectively, and 4.07 and 543.54 times higher than that in serum. Chen et al. [31] reported that GGT in seminal plasma was mainly from prostate, which could be used to evaluate the secretion function of prostate instead of ACP, and that the accuracy of seminal plasma GGT detection was superior to that of ACP. However, studies on the detection of AKP in human seminal plasma were limited [7]. In boar [32] and stallion [13], the level of AKP in seminal plasma was significantly correlated with semen volume and sperm concentration. In bull [33], after semen was frozen and thawed, the level of AKP in seminal plasma increased significantly with sperm motility and fertilization rate decreasing, indicating that $\mathrm{AKP}$ in seminal plasma might come from the secretion of reproductive tract epithelial cells and the release of damaged sperm. However, the source of AKP in seminal plasma and its role in male reproduction need to be further investigated.

Our results also showed that $\mathrm{LDH}, \mathrm{CK}$, and $\alpha \mathrm{HBDH}$ were rich in seminal plasma, up to $14.32,15.37$, and 24.06 times higher than those in serum, respectively. There were also some ADA in seminal plasma. The level of LDH in seminal plasma was similar to those in other published results $[7,17$, 34]. It was well known that lactic acid could be converted to pyruvic acid catalyzed by $\mathrm{LDH}$, which played a role in the production of ATP in sperm mitochondria [35]. Similarly, there was CK in sperm $[36,37]$, which was very important for sperm energy metabolism. Such high LDH and CK concentrations in seminal plasma might suggest that LDH and CK could be used as the marker to predict whether sperm energy metabolism is normal. Therefore, it is necessary to further analyse their origins and potential physiological functions. Recently, a PubMed search showed that the detection of $\alpha \mathrm{HBDH}$ and ADA in seminal plasma has not been found in 
MEDLINE database, and their possible physiological roles in male reproduction remain unclear.

The results in the determination of TG, TC, Glu, UA, hsCRP, Ur, and Cr in seminal plasma showed that the level of UA was similar to that in serum, while the levels of Ur and $\mathrm{Cr}$ were significantly (4.49 and 6.15 times) higher than those in serum, respectively. In contrast, the levels of TG and TC in seminal plasma were only about $1 / 5$ of those in serum, and hsCRP was only about $1 / 10$ of that in serum, and the level of Glu in seminal plasma was extremely low, even undetectable in 8 out of 36 cases, which may be due to the fact that fructose is the main energy source for sperm capitation.

It was shown that the level of UA in seminal plasma from normal fertile men was significantly higher than that from patients with azoospermia, infertility, or the vasectomized [38]. Moreover, the level of UA in seminal plasma was significantly correlated with sperm count [38] and the percentage of sperm with normal morphology [39]. All these reported findings indicated that the UA in seminal plasma might come from testis and/or epididymis and play an important role in protecting sperm from the damage of free radicals [40]; thus, UA could be used as an antioxidation marker in clinical diagnosis. In addition, investigations on $\mathrm{Ur}, \mathrm{Cr}$ $[7,38]$, and hsCRP [41] in seminal plasma were very limited; thus meaningful information was not available. At least three questions remain unclear: (1) whether the hsCRP in seminal plasma was a kind of stress protein in male reproductive system, (2) whether the Ur and $\mathrm{Cr}$ in seminal plasma were the products of sperm metabolism, and (3) what their possible physiological function and clinical significance were.

There was rich cholesterol in human sperm cell membrane, which played an important role in maintaining the normal function of sperm. It was shown that there were exchanges of cholesterol and phospholipids between sperm and seminal plasma [42]. Therefore, it was possible that the level of cholesterol in seminal plasma would lead to the disorder of the cholesterol in sperm cell membrane. Although Meseguer et al. [43] reported no significant correlation of the concentration of cholesterol in seminal plasma with the level in sperm cell membrane, Cross [44] revealed that the medium with rich cholesterol could inhibit the acrosome reaction induced by progesterone. All these observations suggested that the extremely high or low concentration of cholesterol in human seminal plasma could affect the exchange of cholesterol between sperm and seminal plasma, and the detection of cholesterol in sperm cell membrane may be more meaningful than that in seminal plasma.

There were many reports about the detection of electrolytes in seminal plasma, but the results were not entirely consistent, which might be related to the different detection methods. Our results showed that the levels of $\mathrm{Na}^{+}$and $\mathrm{Cl}^{-}$ in seminal plasma were about $1 / 2$ to $2 / 3$ of them in serum, while the levels of $\mathrm{K}^{+}, \mathrm{Ca}, \mathrm{Mg}$, and $\mathrm{P}$ in seminal plasma were significantly higher than them in serum, especially for $\mathrm{P}$ up to 23.73 times. Moreover, there were significantly positive correlations between the levels of $\mathrm{Na}^{+}$and $\mathrm{Cl}^{-}(r=0.654$, $P=0.000)$ and between $\mathrm{Ca}$ and $\mathrm{Mg}(r=0.930, P=0.000)$. In general, there were parallel concentrations of $\mathrm{Na}^{+}$and $\mathrm{Cl}^{-}$ in seminal plasma, and both were significantly higher than those of $\mathrm{K}^{+}$. In contrast, the concentration of $\mathrm{K}^{+}$in sperm was significantly higher than that of $\mathrm{Na}^{+}[45]$.

It was shown that the levels of $\mathrm{Na}^{+}, \mathrm{Ca}$, and $\mathrm{Mg}$ in seminal plasma were positively correlated with the percentage of motile sperm $[46,47]$, while that of $\mathrm{K}^{+}$was inversely correlated [47], indicating that $\mathrm{K}^{+}$in seminal plasma might inhibit sperm motility, but $\mathrm{Na}^{+}$promotes it. There were specific ion channels in sperm cell membrane for transferring $\mathrm{K}^{+}, \mathrm{Na}^{+}$, and $\mathrm{Ca}^{2+}$ into sperm or seminal plasma; accordingly sperm membrane potential changed and sperm motility promoted [48]. Therefore, the levels of electrolyte ions in seminal plasma should have an optimal range, and the increase and decrease of these ions will lead to the disorders of sperm motility [49]. However, whether these ions can be used to evaluate sperm motility needs to be confirmed.

There were very few reports about the detection of $\mathrm{P}$ in seminal plasma. Adamopoulos and Deliyiannis [50] found that there was higher level of $\mathrm{P}$ in seminal plasma in the patients with asthenospermia and lower level in patients with azoospermia compared with the males with normal sperm and that the level of $\mathrm{P}$ was positively correlated with that of fructose in patients with asthenospermia, oligospermia, or azoospermia, indicating that the origin of $\mathrm{P}$ in seminal plasma might be the secretion of seminal vesicle, and the detection of $\mathrm{P}$ in seminal plasma might reflect the secretion function of seminal vesicle.

In summary, among all the 26 biochemical markers we studied, only the level of UA was no significant difference in seminal plasma and serum. There were rich proteins in seminal plasma, but unlike serum, globulin was the dominant protein. There were also rich enzymes in seminal plasma, and the activities of ALT, AST, AKP, GGT, LDH, CK, and $\alpha \mathrm{HBDH}$ except ADA in seminal plasma were significantly higher than those in serum. There were low levels of Glu, TG, TC, and hsCRP in seminal plasma, Glu was undetectable in 8 out of 36 cases, and PA was undetectable in all subjects. At present, the causes leading to the difference of these markers in seminal plasma and serum were unclear, due to the selective secretion of testis, epididymis and male accessory glands, and the specific environment required for sperm metabolism and function maintenance. The limitation of this pilot comparative study was relatively small sample size. Thus, further investigations should be focused on the identification of the origins and potential roles of these biochemical components in male reproduction, and comparison of the difference between fertile and infertile men based on bigger sample size.

\section{Conflict of Interests}

The authors declare that there is no conflict of interests regarding the publication of this paper.

\section{Acknowledgment}

The authors would like to express special thanks to Mr. Yong Shao, Department of Reproduction and Genetics, Jinling Hospital, School of Medicine, Nanjing University, for the contribution in the collection of semen samples. 


\section{References}

[1] J.-C. Lu, H.-R. Xu, F. Chen, Y.-F. Huang, and N.-Q. Lu, "Standardization and quality control for the determination of alphaglucosidase in seminal plasma," Archives of Andrology, vol. 52, no. 6, pp. 447-453, 2006.

[2] J.-C. Lu, H.-R. Xu, Y.-F. Huang, and N.-Q. Lu, "Preliminary investigations on the standardization and quality control for the determination of acid phosphatase activity in seminal plasma," Clinica Chimica Acta, vol. 375, no. 1-2, pp. 76-81, 2007.

[3] J.-C. Lu, F. Chen, H.-R. Xu, Y.-F. Huang, and N.-Q. Lu, "Standardization and quality control for determination of fructose in seminal plasma," Journal of Andrology, vol. 28, no. 2, pp. 207213, 2007.

[4] B. Macanovic, M. Vucetic, A. Jankovic et al., "Correlation between sperm parameters and protein expression of antioxidative defense enzymes in seminal plasma: a pilot study," Disease Markers, vol. 2015, Article ID 436236, 5 pages, 2015.

[5] R. Sharma, A. Agarwal, G. Mohanty et al., "Functional proteomic analysis of seminal plasma proteins in men with various semen parameters," Reproductive Biology and Endocrinology, vol. 11, no. 1, article 38, 2013.

[6] F. Chen, J.-C. Lu, H.-R. Xu, Y.-F. Huang, and N.-Q. Lu, "Chymotrypsin effects on the determination of sperm parameters and seminal biochemistry markers," Clinical Chemistry and Laboratory Medicine, vol. 44, no. 11, pp. 1335-1339, 2006.

[7] I. H. Hirsch, R. S. Jeyendran, J. Sedor, R. R. Rosecrans, and W. E. Staas, "Biochemical analysis of electroejaculates in spinal cord injured men: comparison to normal ejaculates," Journal of Urology, vol. 145, no. 1, pp. 73-76, 1991.

[8] R. R. Rosecrans, R. S. Jeyendran, M. Perez-Pelaez, and W. P. Kennedy, "Comparison of biochemical parameters of human blood serum and seminal plasma," Andrologia, vol. 19, no. 6, pp. 625-628, 1987.

[9] M. Aloosh, M. Hassani, and M. Nikoobakht, "Seminal plasma magnesium and premature ejaculation: a case-control study," BJU International, vol. 98, no. 2, pp. 402-404, 2006.

[10] R.-S. Zhang, H.-J. Sun, and L.-W. Zheng, "Correlation of the contents of trace elements in male body fluids with sperm quality," Zhonghua Nan Ke Xue, vol. 16, no. 11, pp. 1019-1022, 2010.

[11] M. Alvarez, M. Nicolas, S. Borragán et al., “The percentage of spermatozoa lost during the centrifugation of brown bear (Ursus arctos) ejaculates is associated with some spermatozoa quality and seminal plasma characteristics," Animal Reproduction Science, vol. 135, no. 1-4, pp. 113-121, 2012.

[12] W. F. Shaaban, T. A. Taha, F. D. El-Nouty, A. R. El-Mahdy, and M. H. Salem, "Reproductive toxicologic effects of gossypol on male rabbits: biochemical, enzymatic, and electrolytic properties of seminal plasma," Fertility and Sterility, vol. 89, no. 5, pp. 1585-1593, 2008.

[13] S. Pesch, M. Bergmann, and H. Bostedt, "Determination of some enzymes and macro- and microelements in stallion seminal plasma and their correlations to semen quality," Theriogenology, vol. 66, no. 2, pp. 307-313, 2006.

[14] S. Mosaferi, A. Niasari-Naslaji, A. Abarghani, A. A. Gharahdaghi, and A. Gerami, "Biophysical and biochemical characteristics of bactrian camel semen collected by artificial vagina," Theriogenology, vol. 63, no. 1, pp. 92-101, 2005.
[15] M. von Wolff, S. Rösner, C. Thöne et al., "Intravaginal and intracervical application of seminal plasma in in vitro fertilization or intracytoplasmic sperm injection treatment cyclesa double-blind, placebo-controlled, randomized pilot study," Fertility and Sterility, vol. 91, no. 1, pp. 167-172, 2009.

[16] R. Sharma, A. Agarwal, G. Mohanty et al., "Proteomic analysis of seminal fluid from men exhibiting oxidative stress," Reproductive Biology and Endocrinology, vol. 11, no. 1, article 85, 2013.

[17] A. J. Verdejo, E. O. C. de Albornoz, A. L. Maldonado, J. J. Verdejo, and A. Z. Gómez, "Estudio comparativo de determinados parámetros bioquímicos en semen de sujetos vasectomizados y no vasectomizados," Archivos Espanoles de Urologia, vol. 51, no. 8, pp. 811-817, 1998.

[18] S. Kumar, A. K. Tomar, S. Singh et al., "Human serum albumin as a new interacting partner of prolactin inducible protein in human seminal plasma," International Journal of Biological Macromolecules, vol. 50, no. 2, pp. 317-322, 2012.

[19] S. Elzanaty, J. Erenpreiss, and C. Becker, "Seminal plasma albumin: origin and relation to the male reproductive parameters," Andrologia, vol. 39, no. 2, pp. 60-65, 2007.

[20] T. Chard, J. Parslow, T. Rehmann, and A. Dawnay, "The concentrations of transferrin, $\beta 2$-microglobulin, and albumin in seminal plasma in relation to sperm count," Fertility and Sterility, vol. 55, no. 1, pp. 211-213, 1991.

[21] C. Orlando, R. Casano, G. Forti et al., "Immunologically reactive albumin-like protein in human testis and seminal plasma," Journal of Reproduction and Fertility, vol. 83, no. 2, pp. 687-692, 1988.

[22] S. H. Emara and M. Farid, "Total proteins and electrophoretic patterns in seminal plasma of normospermic, azoospermic and oligospermic men," Acta Medica Academiae Scientiarum Hungaricae, vol. 35, no. 2, pp. 167-171, 1978.

[23] J. F. Guerin, Y. Menezo, and J. C. Czyba, "Enzyme comparative study of spermatozoa and seminal plasma in normal and subfertile man," Archives of Andrology, vol. 3, no. 3, pp. 251-257, 1979.

[24] D. Mortimer and T. A. Bramley, "Glutamic-oxalacetic transaminase leakage from human spermatozoa as an indicator of cryodamage," Archives of Andrology, vol. 6, no. 4, pp. 337-341, 1981.

[25] A. J. Dhami and S. B. Kodagali, "Freezability, enzyme leakage and fertility of buffalo spermatozoa in relation to the quality of semen ejaculates and extenders," Theriogenology, vol. 34, no. 5, pp. 853-863, 1990.

[26] J. Giner, M. Mondragon, and G. Zamora, "Fructose, proteins, oxalacetic and pyruvic transaminases in seminal plasma in vasectomized males," Archivos de Investigacion Medica, vol. 7, no. 2, pp. 71-76, 1976.

[27] R. U. Khan, V. Laudadio, and V. Tufarelli, "Semen traits and seminal plasma biochemical parameters in white leghorn layer breeders," Reproduction in Domestic Animals, vol. 47, no. 2, pp. 190-195, 2012.

[28] M. I. Yousef, G. A. Abdallah, and K. I. Kamel, "Effect of ascorbic acid and vitamin E supplementation on semen quality and biochemical parameters of male rabbits," Animal Reproduction Science, vol. 76, no. 1-2, pp. 99-111, 2003.

[29] S. F. Bilgili, J. A. Renden, and K. J. Sexton, "Fluorometry of poultry semen: its application in the determination of viability, enzyme leakage, and fertility," Poultry Science, vol. 64, no. 6, pp. 1227-1230, 1985.

[30] P. Forejtek and S. Návratil, "Relation between aspartate aminotransferase (AST) activity in the seminal fluid and indicators of 
boar ejaculate quality," Veterinarni Medicina, vol. 29, no. 4, pp. 217-222, 1984.

[31] F. Chen, J.-C. Lu, H.-R. Xu, Y.-F. Huang, Y.-A. Hu, and Y. Shao, "Evaluation of the determination of seminal ACP and $\gamma$-GT activities and correlation between seminal ACP or $\gamma$-GT activity and semen parameters," Zhonghua Nan Ke Xue, vol. 12, no. 10, pp. 879-882, 2006.

[32] A. L. Rodríguez, T. Rijsselaere, J. Beek, P. Vyt, A. Van Soom, and D. Maes, "Boar seminal plasma components and their relation with semen quality," Systems Biology in Reproductive Medicine, vol. 59, no. 1, pp. 5-12, 2013.

[33] T. L. Blanchard, D. D. Varner, S. P. Brinsko, and C. C. Love, "Azoospermia in stallions: determining the cause," Compendium: Continuing Education for Veterinarians, vol. 34, pp. E1E8, 2012.

[34] T. Tsujii, T. Kamai, H. Moriguchi et al., "Seminal lactate dehydrogenase $\mathrm{C} 4$ (LDH-C4) isozyme activity in infertile men," Hinyokika Kiyo, vol. 48, no. 4, pp. 193-197, 2002.

[35] R. P. Singh, K. V. H. Sastry, N. K. Pandey et al., "Characterization of lactate dehydrogenase enzyme in seminal plasma of Japanese quail (Coturnix coturnix japonica)," Theriogenology, vol. 75, no. 3, pp. 555-562, 2011.

[36] K. Miyaji, S. Kaneko, H. Ishikawa et al., "Creatine kinase isoforms in the seminal plasma and the purified human sperm," Archives of Andrology, vol. 46, no. 2, pp. 127-134, 2001.

[37] C. Rolf, H. M. Behre, T. G. Cooper, B. Koppers, and E. Nieschlag, "Creatine kinase activity in human spermatozoa and seminal plasma lacks predictive value for male fertility in in vitro fertilization," Fertility and Sterility, vol. 69, no. 4, pp. 727734, 1998.

[38] A. Srivastava, S. K. Chopra, and P. R. Dasgupta, "Biochemical analysis of human seminal plasma II. Protein, non-protein nitrogen, urea, uric acid and creatine," Andrologia, vol. 16, no. 3, pp. 265-268, 1984.

[39] H.-Y. Zhang, J.-C. Lu, R.-S. Zhang, Y.-X. Xia, and Y.-F. Huang, "Determination of uric acid in seminal plasma and correlation between seminal uric acid and semen parameters," Zhonghua Nan Ke Xue, vol. 13, no. 11, pp. 1016-1019, 2007.

[40] R. Kand'ár, P. Drábková, and R. Hampl, “The determination of ascorbic acid and uric acid in human seminal plasma using an HPLC with UV detection," Journal of Chromatography B: Analytical Technologies in the Biomedical and Life Sciences, vol. 879, no. 26, pp. 2834-2839, 2011.

[41] M. Ludwig, C. Kummel, I. Schroeder-Printzen, R.-H. Ringert, and W. Weidner, "Evaluation of seminal plasma parameters in patients with chronic prostatitis or leukocytospermia," Andrologia, vol. 30, no. 1, pp. 41-47, 1998.

[42] L. Huacuja, N. M. Delgado, L. Calzada et al., "Exchange of lipids between spermatozoa and seminal plasma in normal and pathological human semen," Archives of Andrology, vol. 7, no. 4, pp. 343-349, 1981.

[43] M. Meseguer, N. Garrido, J. A. Martínez-Conejero, C. Simón, A. Pellicer, and J. Remohí, "Role of cholesterol, calcium, and mitochondrial activity in the susceptibility for cryodamage after a cycle of freezing and thawing," Fertility and Sterility, vol. 81, no. 3, pp. 588-594, 2004.

[44] N. L. Cross, "Effect of cholesterol and other sterols on human sperm acrosomal responsiveness," Molecular Reproduction and Development, vol. 45, no. 2, pp. 212-217, 1996.

[45] A. H. Colagar, E. T. Marzony, and M. J. Chaichi, "Zinc levels in seminal plasma are associated with sperm quality in fertile and infertile men," Nutrition Research, vol. 29, no. 2, pp. 82-88, 2009.
[46] J. Valsa, K. P. Skandhan, P. H. Gusani, P. S. Khan, and S. Amith, "Quality of 4-hourly ejaculates-levels of calcium and magnesium," Andrologia, vol. 45, no. 1, pp. 10-17, 2013.

[47] P. H. Gusani, K. P. Skandhan, C. Valsa, and Y. D. Menta, "Sodium and potassium in normal and pathological seminal plasma," Acta Europaea Fertilitatis, vol. 23, no. 1, pp. 39-42, 1992.

[48] S. M. H. Alavi and J. Cosson, "Sperm motility in fishes. (II) Effects of ions and osmolality: a review," Cell Biology International, vol. 30, no. 1, pp. 1-14, 2006.

[49] K. P. Skandhan and B. N. Mazumdar, "Correlation of sodium and potassium in human seminal plasma with fertilizing capacity of normal, and infertile subjects," Andrologia, vol. 13, no. 2, pp. 147-153, 1981.

[50] D. A. Adamopoulos and V. Deliyiannis, "Seminal plasma magnesium, calcium and inorganic phosphate concentration in normozoospermic and subfertile men," Andrologia, vol. 15, no. 6, pp. 648-654, 1983. 


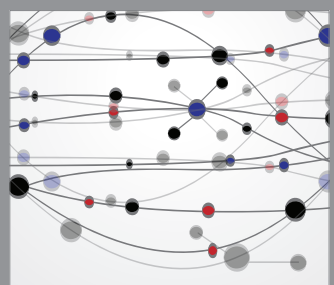

The Scientific World Journal
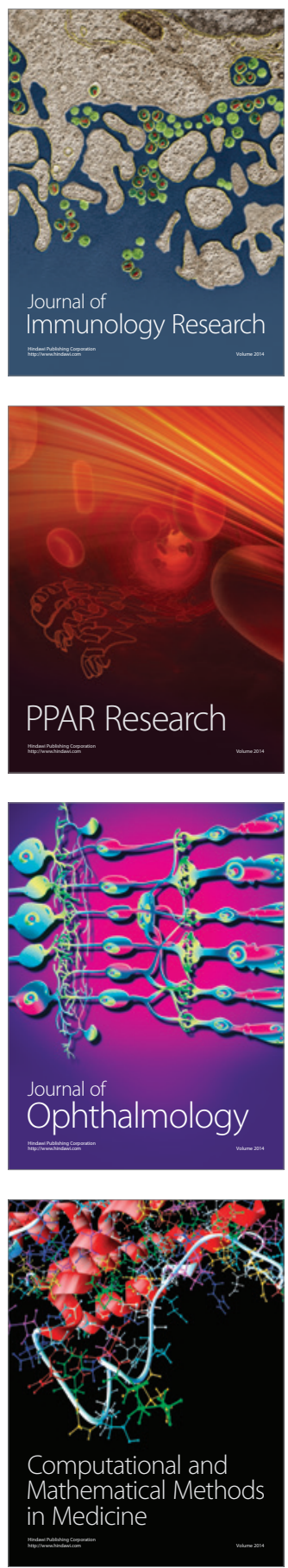

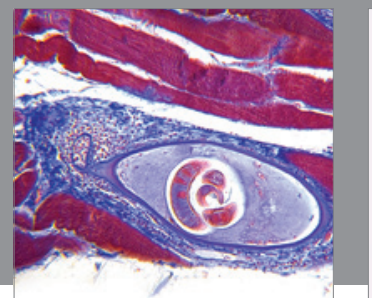

Gastroenterology

Research and Practice
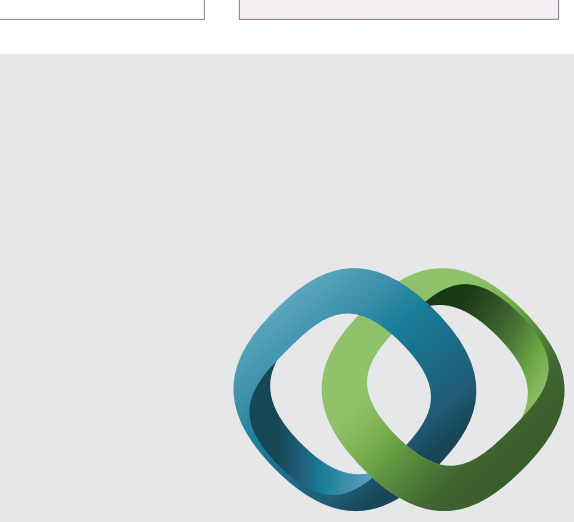

\section{Hindawi}

Submit your manuscripts at

http://www.hindawi.com
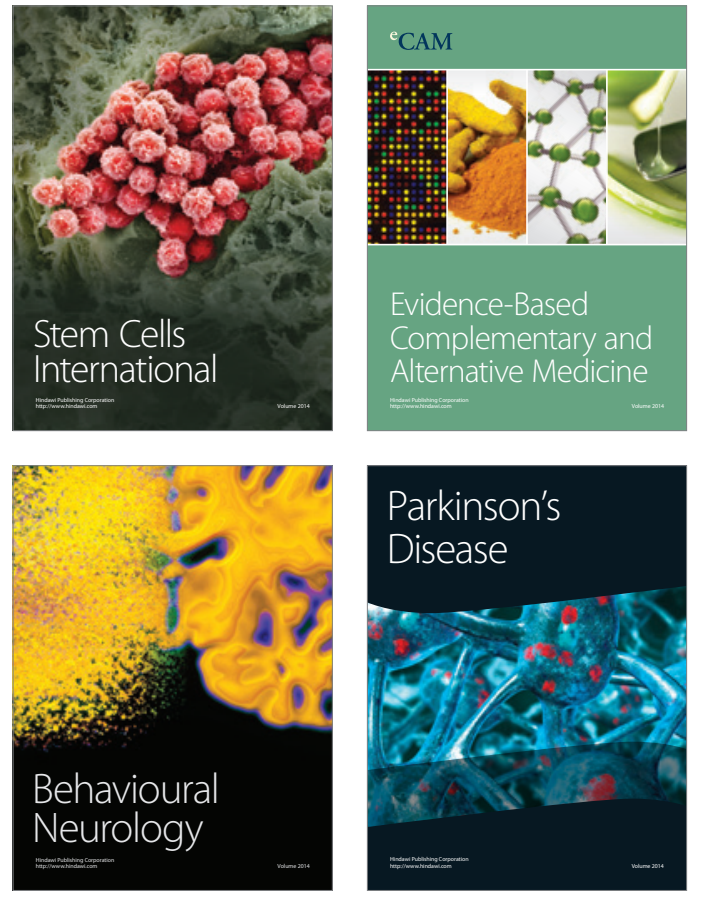
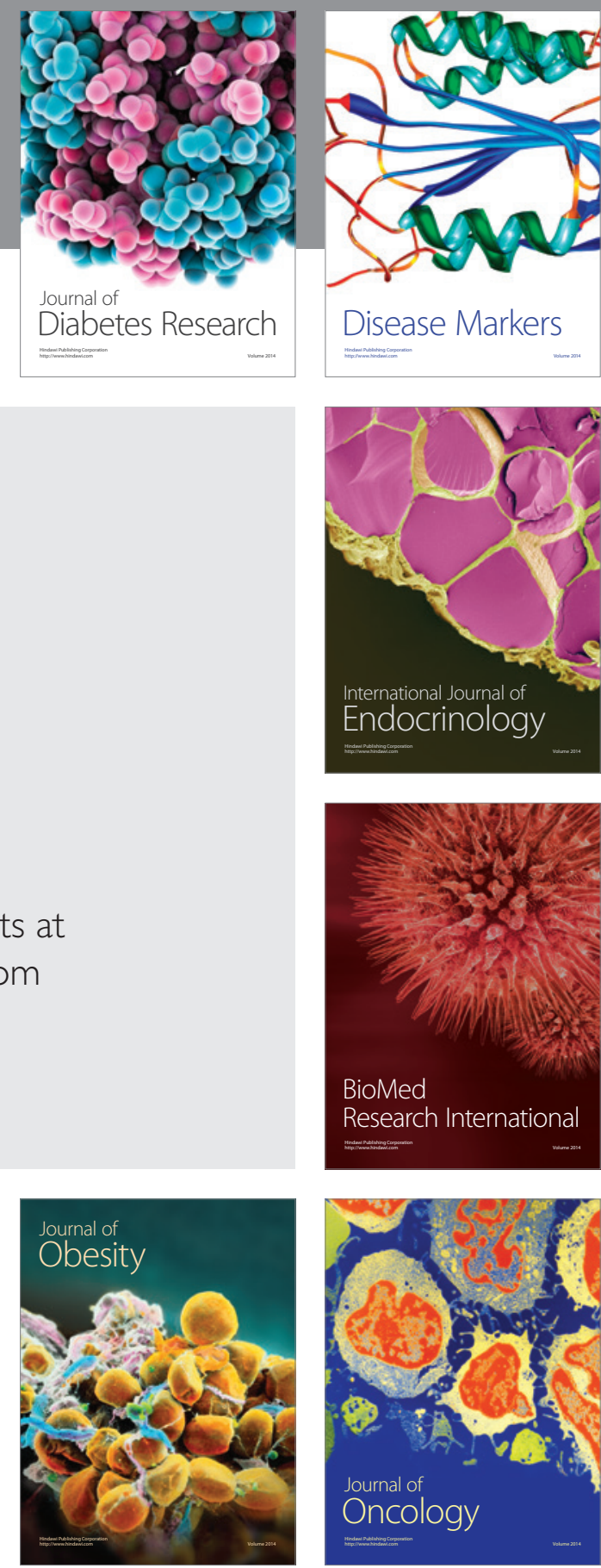

Disease Markers
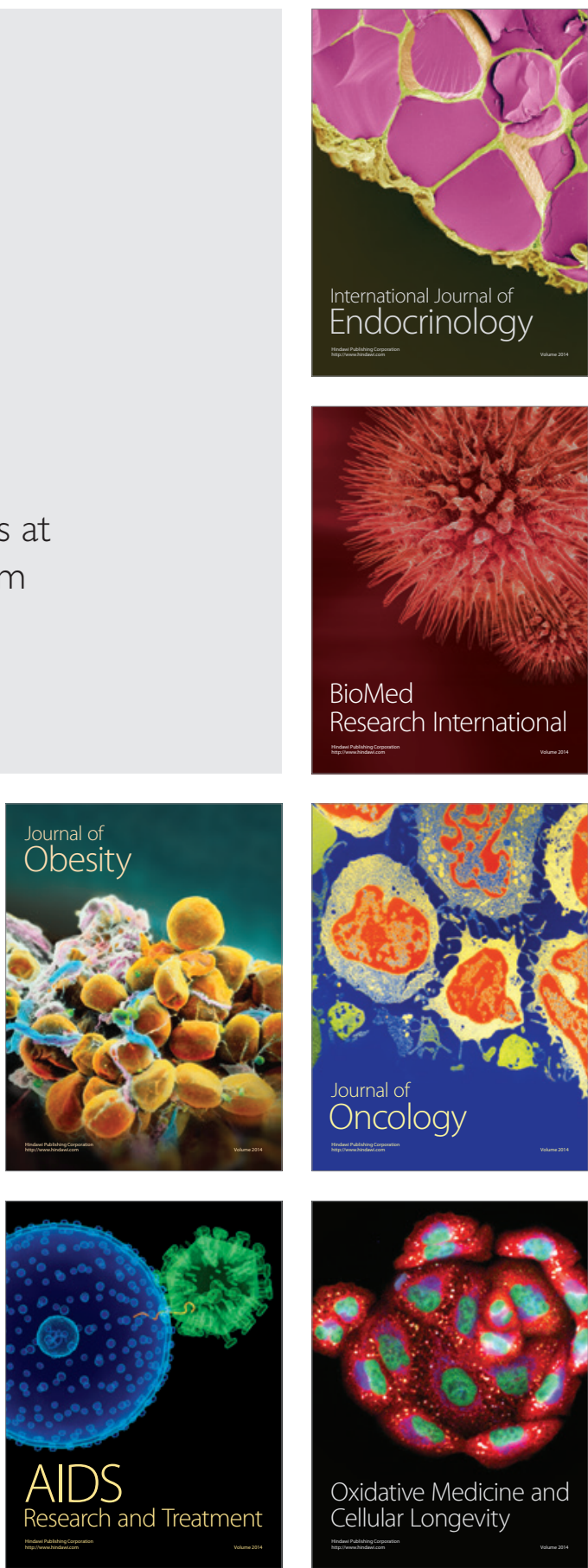